\title{
Intellectual Humility and Perceptions of Political Opponents
}

\author{
Matthew L. Stanley, Alyssa H. Sinclair, and Paul Seli
}

Duke University

Author Note

Matthew L. Stanley, Department of Psychology and Neuroscience, Center for Cognitive Neuroscience, Duke University

Alyssa H. Sinclair, Department of Psychology and Neuroscience, Center for Cognitive Neuroscience, Duke University

Paul Seli, Department of Psychology and Neuroscience, Center for Cognitive

Neuroscience, Duke University

Correspondence should be addressed to Matthew L. Stanley, Department of Psychology \& Neuroscience, 417 Chapel Drive, Duke University, Durham, NC 27708, USA. E-mail: matthew.stanley@duke.edu

De-identified data from all studies are available at https://osf.io/yudz7/

Word count (Introduction, Discussion, Acknowledgments): 1,907 


\begin{abstract}
The epistemic virtue of intellectual humility (IH) refers to the recognition that personal beliefs might be wrong. In four initial studies, we examined the role of IH in predicting how people perceive their sociopolitical opponents, and the role of IH in people's willingness to befriend their sociopolitical opponents. We found that people lower in IH are more likely to derogate and less likely to befriend their opponents. In two additional studies, we experimentally explored a possible method with which to make people less likely to derogate opponents and more willing to befriend them. After informing participants about the results of our existing studies showing that people who hold opposing positions do not differ in $\mathrm{IH}$, participants were less likely to derogate opponents and somewhat more willing to befriend them. We discuss the implications of these results for sincere, open discussion, and for reducing social extremism and polarization. Keywords: intellectual humility, ethics, person perception, politics, polarization
\end{abstract}




\section{Intellectual Humility and Perceptions of Political Opponents}

When confronted with disagreements over social and political issues, many people are highly motivated to maintain their own existing beliefs at the expense of attempting to understand why others hold opposing positions (Porter \& Schumann, 2018; Stanley et al., in press; Lodge \& Taber, 2013). Several pervasive biases play systematic roles in helping people to disregard reasons, arguments, and evidence for positions that conflict with their own beliefs (Kunda, 1990; Lodge \& Taber, 2013; Taber \& Lodge, 2006). For contentious, polarized issues (e.g., gun control; Taber \& Lodge, 2006) and even for less-charged issues (e.g., standardized testing in public schools; Stanley et al., in press), these biases encourage people to be highly resistant to changing their views in the face of opposing reasons and arguments. Indeed, people's beliefs in the superiority of their own sociopolitical positions are commonly held with tremendous confidence (Lodge \& Taber, 2013; Stanley et al., in press). This persistent and confident adherence to personal sociopolitical positions has stifled sincere, fact-based, and open discussion over the merits and problems accompanying the endorsement of certain positions.

However, people differ in the confidence with which they maintain their sociopolitical positions, and in the degree to which they are willing to entertain the possibility that their own positions might be inferior to alternative positions. Intellectual humility (IH) refers to the recognition that personal beliefs might be wrong and is accompanied by a willingness to consider the limitations in the evidentiary basis of one's own personal beliefs, as well as awareness of one's limitations in obtaining and evaluating information that can inform one's beliefs (Leary et al., 2017). Accordingly, low IH often manifests as unfounded confidence in the superiority of one's own views, and as an unwillingness to take seriously the reasons and arguments for opposing positions (Leary et al., 2017; Porter \& Schumann, 2018). In contrast, high IH often 
manifests as even-handed, extensive deliberation over the strength of evidence for factual claims (Deffler, Leary, \& Hoyle, 2016; Leary et al., 2017), along with an interest in listening to the reasons and arguments that favor opponent views (Porter \& Schumann, 2018).

Recent findings suggest that people reporting low IH tend to overconfidently maintain their beliefs and are often unwilling to even-handedly process the reasons and arguments of their opponents (Leary et al., 2017; Porter \& Schumann, 2018). However, it is unclear how those low in IH might justify or facilitate such cognitions, especially when disagreements about sociopolitical issues arise. This raises the question: how do low-IH people maintain overconfidence in their positions and an unwillingness to consider opposing sociopolitical positions? Here, we explore one possible answer to this question: people who are low in IH might derogate the character, competence, and capabilities of their opponents. On this view, by regarding sociopolitical opponents as unintelligent and/or unethical, low-IH people possess a justification for maintaining their beliefs with high confidence, and for dismissing their opponents' reasons and arguments.

Providing indirect support for this proposal, those who exhibit lower IH tend to be less agreeable (Leary et al., 2017; Meagher, Leman, Bias, Latendresse, \& Rowatt, 2015), less empathic (Krumrei-Mancuso, 2017), less open to ideas (Krumrei-Mancuso \& Rouse, 2016), and less likely to generate respectful attributions for why opponents might disagree with them (e.g., because the issue is complex; Porter \& Schumann, 2018). Relatedly, people who are lower in IH tend to be less accepting of those who hold different religious beliefs (Leary et al., 2017). Given these findings, low-IH people might derogate the character and intellect of sociopolitical opponents, which would allow them to more easily dismiss their opponents' reasons and arguments and, consequently, to maintain their existing beliefs with high confidence. 
If, in fact, people who are low in IH tend to derogate their sociopolitical opponents as unintelligent and unethical, then we might also expect them to be less willing to befriend people who hold opposing views, yet quite willing to befriend those with the same views. This might, in turn, create small communities of people who maintain the same sociopolitical views and preferentially seek out and exchange information that reinforces their views. And given the contemporary ubiquity and accessibility of social media platforms, there is no shortage of opportunities for people to create and find their desired communities (Barberá, Jost, Nagler, et al., 2015; Williams, McMurray, Kurz, \& Lambert, 2015; Del Vicario, Vivaldo, et al., 2016). Such "cliques" would be shielded from conflicting views, along with the reasons, arguments, and evidence supporting those conflicting views. This would not only stymie intellectual development, but it would also create an environment in which social extremism and political polarization flourish (Barbera, et al., 2015; Iyengar \& Hahn, 2009).

Here, in four initial studies, we addressed two general hypotheses. First, we explored the possibility that individual differences in IH would predict how people perceive sociopolitical opponents. We hypothesized that those lower in $\mathrm{IH}$ (relative to those higher in $\mathrm{IH}$ ) would derogate the intellectual capabilities and moral character of sociopolitical opponents, and that such low-IH people would have more-negative overall impressions of their opponents. To address this hypothesis, we used both highly-contentious, polarized sociopolitical issues (e.g., abortion; Study 1a) and less-contentious, polarized sociopolitical issues (e.g., standardized testing in public schools; Study 1b). By varying the contentiousness of these issues, we could examine the extent to which the hypothesized outcome generalized across issues. To preview, in Studies 1a and 1b, we found that those lower in IH tended to derogate the intellectual capabilities 
and moral character of sociopolitical opponents for five of the six sociopolitical issues examined (however, we found no relationship between IH and overall impressions of opponents).

We then reasoned that if, in fact, low-IH individuals tend to derogate the intellectual capabilities and moral character of socio-political opponents, they might also be less willing to befriend those opponents. We hypothesized that those lower in IH (relative to those higher in $\mathrm{IH}$ ) would be less willing to befriend people who hold opposing sociopolitical positions for highly contentious, polarized issues (Study 2a), as well as less-contentious, polarized sociopolitical issues (Study 2b). To preview, for all six sociopolitical issues examined, we found that those lower in IH were indeed less willing to befriend those holding opposing sociopolitical positions.

Having found that IH is associated both with participants' tendency to derogate opponents and with their unwillingness to befriend those holding opposing views, we next experimentally explored a potential way to render participants less likely to derogate opponents and more willing to befriend them (Studies 3a and 3b). To this end, we told participants about some of our empirical findings. In particular, participants were told that people who choose opposing positions on particular sociopolitical issues do not actually score differently on actual measures of IH. Instead, people who choose opposing positions are similarly likely to recognize that their own positions might be wrong. We hypothesized that informing participants that people who hold different positions on an issue do not actually differ on IH will render them less likely to derogate their opponents and more willing to befriend them. To preview, we found that telling participants that those who hold opposing positions do not actually differ on measures of IH makes participants less likely to derogate their opponents and more willing to befriend those with opposing views (at least for one of the two issues examined). 
All six studies were pre-registered (https://osf.io/yudz7/), and we report all participants run, all conditions included, and all independent and dependent measures.

\section{Study 1a}

\section{Method and Materials}

Participants. Four-hundred sixty American residents with at least 50 completed human intelligence tasks (HITs) and an approval rating above $90 \%$ voluntarily participated in this study on Amazon's Mechanical Turk (AMT) for monetary compensation. Seventeen participants failed at least one of two attention checks described below, so data were analyzed with the remaining 443 individuals $\left(M_{\mathrm{age}}=39\right.$ years, $S D=13$, range $\mathrm{age}=[19,76], 174$ females, 267 males $)$. Each of our six studies was run in a single wave of data collection, and data were analyzed only after the required sample size target was met in each study. The sample size was determined prior to data collection in each study. Our primary analyses involve Pearson's correlation coefficients, and we aimed to recruit 145 participants per issue (after exclusions) to have $95 \%$ power to detect medium-sized effects $(r=+/-.30)$. We were unsure about the size of the effects prior to participant recruitment, so we attempted to ensure that we would have adequate power to at least detect medium-sized effects. De-identified data for all studies are available at https://osf.io/yudz7/. All studies reported herein were approved by the Duke Campus IRB.

Materials and procedure. Participants completed two different measures of $\mathrm{IH}$, and the order in which the two scales were administered was randomized across participants. The first IH scale includes 6 items and was developed by Leary and colleagues (2017). Sample items include, for example, "I accept that my beliefs and attitudes may be wrong" and "I recognize the value in opinions that are different from my own." Participants rated each item on a 5-pt scale ranging 
from 1 (strongly disagree) to 5 (strongly agree). Responses were averaged to obtain IH scores

(Table 1), and higher scores reflect greater IH.

Table 1. Means, Standard Deviations, and Reliabilities in Study 1a.

\begin{tabular}{lllll}
\hline Issue & Measure & Mean & SD & $\boldsymbol{\alpha}$ \\
\hline Abortion $(n=145)$ & IH (Leary et al.) & 3.87 & .65 & .84 \\
& Intellectual Capabilities of Opponents & 3.09 & 1.18 & .89 \\
& Moral Character of Opponents & 2.83 & 1.24 & .95 \\
Concealed Carry $(n=150)$ & Overall Impression of Opponents & 2.34 & 1.01 & \\
& IH (Leary et al.) & 3.92 & .81 & .85 \\
& Intellectual Capabilities of Opponents & 2.61 & 1.19 & .91 \\
Immigration $(n=148)$ & Moral Character of Opponents & 2.31 & 1.13 & .92 \\
& Overall Impression of Opponents & 2.67 & .86 & \\
& IH (Leary et al.) & 3.92 & .69 & .88 \\
& Intellectual Capabilities of Opponents & 2.70 & 1.08 & .83 \\
& Moral Character of Opponents & 2.60 & 1.14 & .90 \\
\hline
\end{tabular}

Note. Total $N=443$

We also administered a second scale, the Comprehensive Intellectual Humility Scale (CIHS), which includes 22-items (Krumrei-Mancuso \& Rouse, 2016). This was included to ensure that we obtained converging results with both IH scales. (See Supplementary Table 1 for CIHS descriptive statistics and reliabilities.) Our first attention check was embedded within the CIHS. For this attention check, participants were provided with this additional item: "Please select ' 4 ' on the scale so that we know you are paying attention."

The two IH scales were correlated $(r(441)=.69, p<.001)$ and shared similar relationships with all other variables. In the interest of concision, in the main text below, we report results associated with the IH scale from Leary and colleagues (2017) in the main text below, and we report results associated with the CIHS in the Supplementary Results (see Supplementary Tables 1-6 for all statistics and results).

After completing the two IH scales, participants were randomly assigned to consider one of three contentious, polarized political issues: abortion, concealed carry of firearms, or immigration. Participants first read neutral background information about the issue, after which 
they were instructed to take an initial position by making a binary choice. For example, in the immigration condition, participants could choose between the following: (1) I support the position that immigrants currently living in the United States illegally should be eligible for full United States citizenship if certain requirements are met, or (2) I support the position that immigrants currently living in the United States illegally should not be eligible for full United States citizenship no matter what.

Participants were then asked to answer questions about their perceptions of those who chose the opposing position on the issue. Participants were asked to what extent they agree or disagree that a political opponent is (1) unintelligent, (2) irrational, and (3) ignorant on 5-pt scales $(1=$ strongly disagree, $5=$ strongly agree $)$. Responses to these three questions were averaged to form a composite measure indexing perceived intellectual capabilities (see Table 1 for descriptive statistics and reliabilities). Participants were also asked to what extent they agree or disagree that a political opponent is (1) unethical, (2) immoral, and (3) of bad moral character on 5-pt scales $(1=$ strongly disagree, $5=$ strongly agree $)$. Responses to these three questions were likewise averaged to form a composite measure indexing perceived moral character (see Table 1 for descriptive statistics and reliabilities). Note that all six characteristics are negatively framed, meaning that we expect a negative correlation between $\mathrm{IH}$ and both perceived intellectual capabilities and perceived moral character. Finally, participants provided a rating of their overall impression of people who chose the other position on the issue $(1=$ very negative, 5 = very positive; see Table 1 for descriptive statistics).

Next, participants were asked to report their age, gender, and level of education $(1=$ did not complete high school, 2 = high school degree or equivalent, $3=$ Associate's degree, $4=$ Bachelor's degree, 5 = Graduate or Professional degree), after which they responded to 
questions about their politics. Specifically, for the politics questions, participants were asked to indicate how liberal or conservative they are $(1=$ very liberal, $7=$ very conservative $)$, their party affiliation (Democrat, Republican, Other), and how important their party affiliation is to their own personal identity $(1=$ not at all important, $7=$ very important $)$. Responses to demographics and politics questions were used as variables to control for in stepwise regression models. At the end, we presented the second attention check: "Do you feel that you paid attention, avoided distractions, and took the survey seriously?" Participants responded by selecting one of the following: (1) no, I was distracted; (2) no, I had trouble paying attention; (3) no, I didn't take the study seriously; (4) no, something else affected my participation negatively; or (5) yes. Participants were ensured that their responses would not affect their payment or their eligibility for future studies. Only those participants who selected (5) were included in the analyses. Upon completion, participants were given monetary compensation for their time.

\section{Results}

Zero-order correlations. First, bivariate, zero-order correlation analyses were conducted between IH and the three measures assessing the perception of political opponents, split by issue (abortion, concealed carry, immigration; see Table 2). Notably, for all three political issues, IH was significantly related to the perceived intellectual capabilities and moral character of opponents (all $p$ s <.004). For all three issues, those lower in IH were more likely to believe that people who chose the opposing position were lacking in both intellectual capabilities and moral character. However, we found a significant correlation between IH and overall impressions of opponents only for the abortion issue and not for concealed carry or immigration. 
Table 2. Zero-order correlations split by issue in Study la.

\begin{tabular}{|c|c|c|c|c|c|}
\hline Issue & Measure & (1) & (2) & (3) & (4) \\
\hline \multirow[t]{4}{*}{ Abortion } & (1) IH (Leary et al.) & - & & & \\
\hline & (2) Intellectual Capabilities of Opponents & $-.25 * *$ & - & & \\
\hline & (3) Moral Character of Opponents & $-.30 * * *$ & $.76 * * *$ & - & \\
\hline & (4) Overall Impression of Opponents & $.18 *$ & $-.39 * * *$ & $-.24 * *$ & - \\
\hline \multirow[t]{4}{*}{ Concealed Carry } & (1) IH (Leary et al.) & - & & & \\
\hline & (2) Intellectual Capabilities of Opponents & $-.37 * * *$ & - & & \\
\hline & (3) Moral Character of Opponents & $-.49 * * *$ & $.78 * * *$ & - & \\
\hline & (4) Overall Impression of Opponents & .05 & $-.24 * * *$ & $-.17 *$ & - \\
\hline \multirow[t]{4}{*}{ Immigration } & (1) IH (Leary et al.) & - & & & \\
\hline & (2) Intellectual Capabilities of Opponents & $-.31 * * *$ & - & & \\
\hline & (3) Moral Character of Opponents & $-.24 * *$ & $.69 * * *$ & - & \\
\hline & (4) Overall Impression of Opponents & .04 & $-.29 * * *$ & $-.34 * * *$ & - \\
\hline
\end{tabular}

Note. $* * * p<.001, * * p<.01, * p<.05$

Stepwise regression analyses. We next computed stepwise hierarchical mixed-effects models to further investigate the relation between IH and the perceived intellectual capabilities and the moral character of opponents, respectively. (We did not compute stepwise hierarchical mixed-effects models to investigate the relationship between IH and overall impressions of opponents because there was only a significant correlation between IH and overall impressions of opponents for the abortion issue. It is unlikely that IH is related to the overall impressions of opponents across issues in a generalizable way.) In these models, issue (abortion, concealed carry, immigration) was included as a random effect. All mixed-effects models reported across all studies were computed with the 'Ime4' package in R (Bates et al., 2014). Then, we conducted separate mixed-effects stepwise regressions for each issue.

First, in Step 1, only IH was included as a fixed-effects term predicting the perceived intellectual capabilities of opponents. See Supplementary Table 7. In Step 2, we included age, gender $(0=$ male, $1=$ female $)$, and education as additional fixed effects. Finally, in Step 3, we included the three political variables as fixed effects in the model: political leaning $(1=$ very liberal, $7=$ very conservative), party affiliation (Democrat, Republican, Other), and importance of party affiliation to personal identity $(1=$ not at all important, $7=$ very important $)$. At each 
step, IH continued to be a strong, significant predictor of the perceived intellectual capabilities of opponents (all $p \mathrm{~s}<.001)$.

This same process was then repeated separately for each issue. For each issue, IH remained a strong, significant predictor of the perceived intellectual capabilities of opponents after each step in the stepwise regression (see Table 3).

Table 3. Results from stepwise regressions models split by issue in Study la with the perceived intellectual capabilities of opponents as the outcome variable.

\begin{tabular}{|c|c|c|c|c|c|c|c|}
\hline \multirow[b]{2}{*}{ Issue } & \multirow[b]{2}{*}{ Variables } & \multicolumn{2}{|c|}{ Step 1} & \multicolumn{2}{|c|}{ Step 2} & \multicolumn{2}{|c|}{ Step 3} \\
\hline & & $b(S E)$ & $95 \% \mathrm{CI}$ & $b(S E)$ & $95 \% \mathrm{CI}$ & $b(S E)$ & $95 \% \mathrm{CI}$ \\
\hline \multirow[t]{9}{*}{ Abortion } & $\mathrm{IH}$ & $-.45(.15)^{* *}$ & {$[-.75,-.16]$} & $-.46(.14)^{* * *}$ & {$[-.74,-.17]$} & $-.45(.14)^{* *}$ & {$[-.73,-.17]$} \\
\hline & Age & & & $-.03(.01)^{* *}$ & {$[-.04,-.01]$} & $-.02(.01)^{* *}$ & {$[-.04, .00]$} \\
\hline & Gender & & & $.18(.19)$ & {$[-.19, .56]$} & $.09(.19)$ & {$[-.28, .46]$} \\
\hline & Education & & & $.00(.09)$ & {$[-.18, .17]$} & $-.03(.08)$ & {$[-.20, .14]$} \\
\hline & Political Leaning & & & & & $-.09(.06)$ & {$[-.20, .03]$} \\
\hline & Party Affiliation & & & & & $-.55(.25)^{*}$ & {$[-1.06,-.05]$} \\
\hline & [T. Republican] & & & & & & \\
\hline & $\begin{array}{l}\text { Party Affiliation } \\
\text { [T. Other] }\end{array}$ & & & & & $-.14(.24)$ & {$[-.61, .34]$} \\
\hline & Political Identity & & & & & $.08(.05)$ & {$[-.02, .19]$} \\
\hline \multirow{8}{*}{$\begin{array}{l}\text { Concealed } \\
\text { Carry }\end{array}$} & $\mathrm{IH}$ & $-.55(.11)^{* * *}$ & {$[-.77,-.33]$} & $-.56(.11)^{* * *}$ & {$[-.78,-.33]$} & $-.53(.12)^{* * *}$ & {$[-.76,-.30]$} \\
\hline & Age & & & $.00(.01)$ & {$[-.02, .01]$} & $.00(.01)$ & {$[-.02, .01]$} \\
\hline & Gender & & & $-.13(.20)$ & {$[-.52, .26]$} & $-.19(.20)$ & {$[-.59, .21]$} \\
\hline & Education & & & $.03(.09)$ & {$[-.14, .21]$} & $.02(.09)$ & {$[-.16, .19]$} \\
\hline & Political Leaning & & & & & $.05(.07)$ & {$[-.09, .18]$} \\
\hline & $\begin{array}{l}\text { Party Affiliation } \\
\text { [T. Republican] }\end{array}$ & & & & & $.02(.30)$ & {$[-.57, .61]$} \\
\hline & $\begin{array}{l}\text { Party Affiliation } \\
\text { [T. Other] }\end{array}$ & & & & & $.07(.28)$ & {$[-.49, .63]$} \\
\hline & Political Identity & & & & & $.14(.06)^{*}$ & {$[.03, .26]$} \\
\hline \multirow{8}{*}{$\begin{array}{l}\text { Immigra- } \\
\text { tion }\end{array}$} & $\mathrm{IH}$ & $-.49(.12) * * *$ & {$[-.73,-.24]$} & $-.50(.12)^{* * *}$ & {$[-.75,-.26]$} & $-.52(.12) * * *$ & {$[-.76,-.28]$} \\
\hline & Age & & & $-.01(.01)$ & {$[-.03, .00]$} & $-.01(.01)$ & {$[-.03, .00]$} \\
\hline & Gender & & & $.19(.17)$ & {$[-.15, .54]$} & $.16(.16)$ & {$[-.16, .49]$} \\
\hline & Education & & & $-.12(.08)$ & {$[-.27, .04]$} & $-.12(.07)$ & {$[-.26, .03]$} \\
\hline & Political Leaning & & & & & $-.14(.06)^{*}$ & {$[-.25,-.02]$} \\
\hline & $\begin{array}{l}\text { Party Affiliation } \\
\text { [T. Republican] }\end{array}$ & & & & & $.20(.25)$ & {$[-.30, .70]$} \\
\hline & $\begin{array}{l}\text { Party Affiliation } \\
\text { [T. Other] }\end{array}$ & & & & & $.26(.23)$ & {$[-.19, .72]$} \\
\hline & Political Identity & & & & & $.16(.05) * *$ & {$[.06, .26]$} \\
\hline
\end{tabular}

Note. $* * * p<.001, * * p<.01, * p<.05$. The outcome variable in all models is the perceived intellectual capabilities of opponents. All $95 \%$ CIs are around beta-estimates.

Next, only IH was included as a fixed-effects term predicting the perceived moral character of opponents in Step 1. Issue was included as a random effect in all models. In Step 2, we included age, gender $(0=$ male, $1=$ female $)$, and education as additional fixed effects. 
Finally, in Step 3, we included in the model the three political variables as fixed effects: political leaning $(1=$ very liberal, $7=$ very conservative $)$, party affiliation (Democrat, Republican, Other), and importance of party affiliation to personal identity $(1=$ not at all important, $7=$ very important). At each step, IH was a robust, significant predictor of the perceived moral character of opponents (all $p$ s <.001). See Supplementary Table 8 for full results.

This same process was then executed for each issue, separately. For each issue, IH remained a strong, significant predictor of the perceived moral character of opponents, even after each step (see Table 4).

Table 4. Results from stepwise regressions models split by issue in Study la with the perceived moral character of opponents as the outcome variable.

\begin{tabular}{|c|c|c|c|c|c|c|c|}
\hline \multirow[b]{2}{*}{ Issue } & \multirow[b]{2}{*}{ Variables } & \multicolumn{2}{|c|}{ Step 1} & \multicolumn{2}{|c|}{ Step 2} & \multicolumn{2}{|c|}{ Step 3} \\
\hline & & $b(S E)$ & $95 \% \mathrm{CI}$ & $b(S E)$ & $95 \% \mathrm{CI}$ & $b(S E)$ & $95 \% \mathrm{CI}$ \\
\hline \multirow[t]{9}{*}{ Abortion } & $\mathrm{IH}$ & $-.58(.15) * * *$ & {$[-.88,-.27]$} & $-.62(.15) * * *$ & {$[-.92,-.32]$} & $-.60(.15)^{* * *}$ & {$[-.90,-.31]$} \\
\hline & Age & & & $-.02(.01)^{*}$ & {$[-.04, .00]$} & $-.01(.01)$ & {$[-.03, .00]$} \\
\hline & Gender & & & $-.20(.20)$ & {$[-.60, .19]$} & $-.27(.20)$ & {$[-.66, .13]$} \\
\hline & Education & & & $-.10(.09)$ & {$[-.28, .08]$} & $-.12(.09)$ & {$[-.30, .06]$} \\
\hline & Political Leaning & & & & & $-.03(.06)$ & {$[-.15, .10]$} \\
\hline & Party Affiliation & & & & & $-.55(.27)^{*}$ & {$[-1.09,-.01]$} \\
\hline & [T. Republican] & & & & & & \\
\hline & $\begin{array}{l}\text { Party Affiliation } \\
\text { [T. Other] }\end{array}$ & & & & & $-.29(.26)$ & {$[-.80, .21]$} \\
\hline & Political Identity & & & & & $.07(.06)$ & {$[-.05, .18]$} \\
\hline \multirow{8}{*}{$\begin{array}{l}\text { Concealed } \\
\text { Carry }\end{array}$} & $\mathrm{IH}$ & $-.68(.10)^{* * *}$ & {$[-.88,-.48]$} & $-.69(.10)^{* * *}$ & {$[-.89,-.49]$} & $-.68(.10)^{* * *}$ & {$[-.88,-.47]$} \\
\hline & Age & & & $-.01(.01)$ & {$[-.02, .00]$} & $-.01(.01)$ & {$[-.02, .00]$} \\
\hline & Gender & & & $.11(.17)$ & {$[-.23, .44]$} & $.06(.18)$ & {$[-.29, .42]$} \\
\hline & Education & & & $.05(.08)$ & {$[-.10, .20]$} & $.04(.08)$ & {$[-.12, .19]$} \\
\hline & Political Leaning & & & & & $.04(.06)$ & {$[-.08, .16]$} \\
\hline & Party Affiliation & & & & & $-.08(.26)$ & {$[-.60, .44]$} \\
\hline & $\begin{array}{l}\text { Party Affiliation } \\
\text { [T. Other] }\end{array}$ & & & & & $.09(.25)$ & {$[-.40, .59]$} \\
\hline & Political Identity & & & & & $.11(.05)^{*}$ & {$[.00, .21]$} \\
\hline \multirow{9}{*}{$\begin{array}{l}\text { Immigra- } \\
\text { tion }\end{array}$} & $\mathrm{IH}$ & $-.40(.13)^{* *}$ & {$[-.66, .13]$} & $-.46(.13) * * *$ & {$[-.72,-.20]$} & $-.47(.13) * * *$ & {$[-.73,-.22]$} \\
\hline & Age & & & $-.02(.01)^{*}$ & {$[-.03, .00]$} & $-.02(.01)^{*}$ & {$[-.03, .00]$} \\
\hline & Gender & & & $-.27(.18)$ & {$[-.63, .10]$} & $-.30(.17)$ & {$[-.65, .04]$} \\
\hline & Education & & & $-.09(.08)$ & {$[-.25, .08]$} & $-.10(.08)$ & {$[-.26, .06]$} \\
\hline & Political Leaning & & & & & $-.12(.06)$ & {$[-.24, .00]$} \\
\hline & Party Affiliation & & & & & $.06(.24)$ & {$[-.48, .59]$} \\
\hline & [T. Republican] & & & & & & \\
\hline & $\begin{array}{l}\text { Party Affiliation } \\
\text { [T. Other] }\end{array}$ & & & & & $.01(.24)$ & {$[-.48, .49]$} \\
\hline & Political Identity & & & & & $.14(.05)^{* *}$ & {$[.04, .25]$} \\
\hline
\end{tabular}


Taken together, these results largely corroborate our first hypothesis: for highly contentious, polarized sociopolitical issues, low-IH individuals were more likely to derogate the intellectual capabilities and moral character of those who hold opposing views. These effects held at a similar magnitude even after statistically controlling for several demographics variables (gender, age, and education) and several variables assessing participants' political beliefs and orientations. However, for the relationship between IH and overall impressions of opponents, we did not find consistent effects across the three issues. Specifically, there was a significant, positive correlation between $\mathrm{IH}$ and overall impressions of opponents for the abortion issue, but there was no significant relationship for concealed carry or immigration.

\section{Study 1b}

\section{Method and Materials}

Participants. Four-hundred sixty American residents with at least 50 completed HITs and an approval rating above 90\% voluntarily participated in this study on Amazon's Mechanical Turk (AMT) for monetary compensation. Seventeen participants failed at least one of two attention checks described below, so data were analyzed with the remaining 443 individuals $\left(M_{\text {age }}=38\right.$ years, $S D=21$, range age $=[18,78], 226$ females, 215 males $)$. As in Study 1a, our primary analyses involve Pearson's correlation, and we aimed to recruit 145 participants per issue (after exclusions) to have $95 \%$ power to detect medium-sized effects $(r=+/-.30)$.

Materials and procedure. The materials and procedure in Study $1 \mathrm{~b}$ were the same as in Study 1a, with one key difference: in Study 1b, we used three new political issues - drone strikes on military targets overseas, fracking, and standardized testing in schools - that are less-charged and less-contentious than those used in Study 1a. Although these three new political issues are topically relevant, they are not constantly in the news, and many citizens may have unsettled 
opinions about them (Stanley et al., in press). The only other difference between Studies 1a and 1b was that, whereas in Study 1a we administered both Leary et al.’s (2017) IH scale and Krumrei-Mancuso and Rouse's (2016) CIHS scale, in Study 1b we administered only Leary et al.'s IH scale. The rationale for this was that, in Study 1a, the two scales provided a high degree of overlap and the same pattern of relationships with our other variables of interest. The same attention check item originally embedded in the CIHS in Study 1a was placed in the IH scale from Leary and colleagues in Study $1 \mathrm{~b}$.

\section{Results}

For the key variables of interest, Table 5 provides descriptive statistics and reliabilities split by political issue.

Table 5. Means, Standard Deviations, and Reliabilities in Study $1 b$.

\begin{tabular}{lllll}
\hline Issue & Measure & Mean & SD & $\boldsymbol{\alpha}$ \\
\hline Drone Strikes $(n=145)$ & IH (Leary et al.) & 3.97 & .70 & .86 \\
& Intellectual Capabilities of Opponents & 2.05 & .93 & .86 \\
& Moral Character of Opponents & 2.14 & 1.04 & .92 \\
& Overall Impression of Opponents & 2.84 & .72 & \\
Fracking $(n=148)$ & IH (Leary et al.) & 3.94 & .61 & .80 \\
& Intellectual Capabilities of Opponents & 2.30 & .91 & .84 \\
& Moral Character of Opponents & 2.23 & .97 & .91 \\
& Overall Impression of Opponents & 2.71 & .73 & \\
Standardized Testing $(n=150)$ & IH (Leary et al.) & 3.97 & 1.08 & .83 \\
& Intellectual Capabilities of Opponents & 2.06 & 1.03 & .87 \\
& Moral Character of Opponents & 1.75 & .99 & .92 \\
\hline
\end{tabular}

Note. Total $N=443$

Zero-order correlations. First, bivariate, zero-order correlations were computed

between IH and the three measures assessing the perception of political opponents, split by issue (drone strikes, fracking, standardized testing; see Table 6). Notably, for both drone strikes and standardized testing issues, IH was significantly related to the perceived intellectual capabilities and moral character of opponents (all $p \mathrm{~s}<.03$ ). For these issues, participants lower in IH were more likely to believe that people who chose the opposing position were lacking in both 
intellectual capabilities and moral character than those higher in $\mathrm{IH}$. However, for the issue of fracking, IH was not significantly related to the perceived intellectual capabilities or moral character of opponents (all ps >.20).

Table 6. Zero-order correlations split by issue in Study $1 b$.

\begin{tabular}{lllll}
\hline Issue & Measure & $\mathbf{( 1 )}$ & $\mathbf{( 2 )}$ & $\mathbf{( 3 )}$ \\
\hline Drone Strikes & (1) IH (Leary et al.) & - & & $\mathbf{( 4 )}$ \\
& (2) Intellectual Capabilities of Opponents & $-.25^{* *}$ & - & - \\
& (3) Moral Character of Opponents & $-.19^{*}$ & $.77^{* * *}$ & - \\
Fracking & (4) Overall Impression of Opponents & $.22^{* *}$ & $-.40^{* * *}$ & $-.39^{* * *}$ \\
& (1) IH (Leary et al.) & - & - \\
& (2) Intellectual Capabilities of Opponents & -.10 & - & - \\
Standardized Testing & (3) Moral Character of Opponents & .04 & $.69^{* * *}$ & - \\
& (4) Overall Impression of Opponents & -.08 & $-.29^{* * *}$ & $-.31^{* * *}$ \\
& (1) IH (Leary et al.) & - & - \\
& (2) Intellectual Capabilities of Opponents & $-.34^{* * *}$ & - & - \\
& (3) Moral Character of Opponents & $-.34^{* * *}$ & $.79^{* * *}$ & - \\
& (4) Overall Impression of Opponents & .13 & $-.17^{*}$ & .06 \\
\hline
\end{tabular}

Note. $* * * p<.001, * * p<.01, * p<.05$

Stepwise regressions. We next computed stepwise hierarchical mixed-effects models to investigate the relation between $\mathrm{IH}$ and the perceived intellectual capabilities and moral character of opponents, respectively. (We do not compute stepwise hierarchical mixed-effects models to further investigate the relationship between $\mathrm{IH}$ and overall impressions of opponents, because there was only a significant correlation between IH and overall impressions of opponents for the drone strikes issue. IH was not related to the overall impressions of opponents across issues in a generalizable way.) In these models, issue (drone strikes, fracking, standardized testing) was included as a random effect. Next, we conducted separate stepwise hierarchical regressions for each issue. This same general process was implemented in Study 1a.

In Step 1, only IH was included as a fixed-effects term predicting the perceived intellectual capabilities of opponents. In all models, issue was included as a random effect. See Supplementary Table 9 for all results. In Step 2, we included age, gender $(0=$ male, $1=$ female), and education as additional fixed effects. Finally, in Step 3, we included, as fixed effects 
in the model, the three political variables: political leaning $(1=$ very liberal, $7=$ very

conservative), party affiliation (Democrat, Republican, Other), and importance of party

affiliation to personal identity $(1=$ not at all important, $7=$ very important $)$. At each step, IH was strongly and significantly predictive of the perceived intellectual capabilities of opponents (all $p \mathrm{~s}$ $<.001)$.

We then repeated this process for drone strikes and standardized testing, separately, because IH was significantly related to the perceived intellectual capabilities of opponents for each issue. For both issues, IH strongly and significantly predicted the perceived intellectual capabilities of opponents after each step (see Table 7).

Table 7. Results from stepwise regressions models split by issue in Study $1 \mathrm{~b}$ with the perceived intellectual capabilities of opponents as the outcome variable.

\begin{tabular}{|c|c|c|c|c|c|c|c|}
\hline \multirow[b]{2}{*}{ Issue } & \multirow[b]{2}{*}{ Variables } & \multicolumn{2}{|c|}{ Step 1} & \multicolumn{2}{|c|}{ Step 2} & \multicolumn{2}{|c|}{ Step 3} \\
\hline & & $b(S E)$ & $95 \% \mathrm{CI}$ & $b(S E)$ & $95 \% \mathrm{CI}$ & $b(S E)$ & $95 \% \mathrm{CI}$ \\
\hline \multirow{9}{*}{$\begin{array}{l}\text { Drone } \\
\text { Strikes }\end{array}$} & $\mathrm{IH}$ & $-.33(.11)^{* *}$ & {$[-.54, .-.12]$} & $-.36(.11) * * *$ & {$[-.57,-.15]$} & $-.36(.11)^{* *}$ & {$[-.58,-.14]$} \\
\hline & Age & & & $-.01(.01)$ & {$[-.03, .00]$} & $-.01(.01)$ & {$[-.02, .00]$} \\
\hline & Gender & & & $-.08(.15)$ & {$[-.38, .21]$} & $-.06(.16)$ & {$[-.37, .25]$} \\
\hline & Education & & & $-.13(.07)$ & {$[-.26, .01]$} & $-.15(.07)^{*}$ & {$[-.28,-.01]$} \\
\hline & Political Leaning & & & & & $.00(.06)$ & {$[-.12, .12]$} \\
\hline & Party Affiliation & & & & & $-.17(.26)$ & {$[-.69, .35]$} \\
\hline & [T. Republican] & & & & & (1) & 厂 10 ( 201 \\
\hline & $\begin{array}{l}\text { Party Affiliation } \\
\text { [T. Other] }\end{array}$ & & & & & $-.01(.20)$ & {$[-.40, .38]$} \\
\hline & Political Identity & & & & & $.04(.04)$ & {$[-.04, .12]$} \\
\hline \multirow{9}{*}{$\begin{array}{l}\text { Standardized } \\
\text { Testing }\end{array}$} & $\mathrm{IH}$ & $-.50(.12) * * *$ & {$[-.73,-.27]$} & $-.49(.12)^{* * *}$ & {$[-.73,-.26]$} & $-.43(.12)^{* * *}$ & {$[-.66,-.19]$} \\
\hline & Age & & & $.00(.01)$ & {$[-.01, .01]$} & $.00(.01)$ & {$[-.02, .01]$} \\
\hline & Gender & & & $-.01(.16)$ & {$[-.33, .32]$} & $-.08(.16)$ & {$[-.40, .24]$} \\
\hline & Education & & & $.04(.08)$ & {$[-.12, .20]$} & $.00(.08)$ & {$[-.16, .16]$} \\
\hline & Political Leaning & & & & & $.14(.06)^{*}$ & {$[.02, .26]$} \\
\hline & Party Affiliation & & & & & $-.21(.25)$ & {$[-.72, .29]$} \\
\hline & [T. Republican] & & & & & & \\
\hline & $\begin{array}{l}\text { Party Affiliation } \\
\text { [T. Other] }\end{array}$ & & & & & $.01(.24)$ & {$[-.46, .48]$} \\
\hline & Political Identity & & & & & $.08(.05)$ & {$[-.01, .18]$} \\
\hline
\end{tabular}

Next, only IH was included as a fixed-effects term predicting the perceived moral character of opponents in Step 1. Issue was included as a random effect in all models. In Step 2, 
we included age, gender $(0=$ male, $1=$ female $)$, and education as additional fixed effects.

Finally, in Step 3, we included the three political variables as fixed effects in the model: political leaning $(1=$ very liberal, 7 = very conservative $)$, party affiliation (Democrat, Republican, Other), and importance of party affiliation to personal identity $(1=$ not at all important, $7=$ very important). At each step, IH was strong, significant predictor of the perceived moral character of opponents (all $p$ s <.001). See Supplementary Table 10 for full results.

We then repeated this process for drone strikes and standardized testing, separately, because IH was significantly related to the perceived moral character of opponents for these two issues. For both issues, IH was robustly and significantly predictive of the perceived moral character of opponents after each step (see Table 8).

Table 8. Results from stepwise regressions models split by issue in Study $1 b$ with the perceived moral character of opponents as the outcome variable.

\begin{tabular}{|c|c|c|c|c|c|c|c|}
\hline \multirow[b]{2}{*}{ Issue } & \multirow[b]{2}{*}{ Variables } & \multicolumn{2}{|c|}{ Step 1} & \multicolumn{2}{|c|}{ Step 2} & \multicolumn{2}{|c|}{ Step 3} \\
\hline & & $b(S E)$ & $95 \% \mathrm{CI}$ & $b(S E)$ & $95 \% \mathrm{CI}$ & $b(S E)$ & $95 \% \mathrm{CI}$ \\
\hline \multirow{9}{*}{$\begin{array}{l}\text { Drone } \\
\text { Strikes }\end{array}$} & $\mathrm{IH}$ & $-.28(.12)^{*}$ & {$[-.52,-.04]$} & $-.29(.12)^{*}$ & {$[-.53,-.06]$} & $-.35(.12) * *$ & {$[-.59,-.10]$} \\
\hline & Age & & & $-.02(.01)^{* *}$ & {$[-.03,-.01]$} & $-.02(.01)^{*}$ & {$[-.03, .00]$} \\
\hline & Gender & & & $-.16(.17)$ & {$[-.50, .17]$} & $-.21(.18)$ & {$[-.56, .14]$} \\
\hline & Education & & & $-.02(.08)$ & {$[-.17, .13]$} & $-.06(.08)$ & {$[-.21, .10]$} \\
\hline & Political Leaning & & & & & $-.11(.07)$ & {$[-.24, .02]$} \\
\hline & Party Affiliation & & & & & $.10(.30)$ & {$[-.49, .68]$} \\
\hline & [T. Republican] & & & & & & \\
\hline & $\begin{array}{l}\text { Party Affiliation } \\
\text { [T. Other] }\end{array}$ & & & & & $.07(.22)$ & {$[-.37, .50]$} \\
\hline & Political Identity & & & & & $.03(.05)$ & {$[-.07, .12]$} \\
\hline \multirow{8}{*}{$\begin{array}{l}\text { Standardized } \\
\text { Testing }\end{array}$} & $\mathrm{IH}$ & $-.49(.11)^{* * *}$ & {$[-.71,-.27]$} & $-.50(.11) * * *$ & {$[-.72,-.27]$} & $-.44(.11) * * *$ & {$[-.67,-.22]$} \\
\hline & Age & & & $-.01(.01)$ & {$[-.02, .00]$} & $-.01(.01)$ & {$[-.02, .00]$} \\
\hline & Gender & & & $.11(.15)$ & {$[-.19, .42]$} & $.04(.16)$ & {$[-.26,35]$} \\
\hline & Education & & & $.09(.08)$ & {$[-.07, .24]$} & $.05(.08)$ & {$[-.10, .21]$} \\
\hline & Political Leaning & & & & & $.11(.06)$ & {$[-.01, .23]$} \\
\hline & $\begin{array}{l}\text { Party Affiliation } \\
\text { [T. Republican] }\end{array}$ & & & & & $-.21(.24)$ & {$[-.69, .27]$} \\
\hline & $\begin{array}{l}\text { Party Affiliation } \\
\text { [T. Other] }\end{array}$ & & & & & $.01(.23)$ & {$[-.44, .46]$} \\
\hline & Political Identity & & & & & $.08(.04)$ & {$[-.01, .17]$} \\
\hline
\end{tabular}

Note. $* * * p<.001,{ }^{* *} p<.01,{ }^{*} p<.05$. Dependent variable in all models is the perceived moral character of opponents. All $95 \%$ CIs are around beta-estimates. 
Taken together, these results extend our findings from Study 1a by using a set of lesscontentious/polarized sociopolitical issues. For the issues concerning drone strikes on military targets overseas and standardized testing, we found that low-IH individuals were more likely to derogate the intellectual capabilities and moral character of those who hold opposing views. These effects held at a similar magnitude even after statistically controlling for several demographics variables and several variables assessing participants' political beliefs and orientations. However, we found no relationship between $\mathrm{IH}$ and the perceived intellectual capabilities or moral character of opponents for attitudes toward fracking. And, as was the case in Study 1a, we did not find a consistent relationship across issues for the relationship between $\mathrm{IH}$ and reported overall impressions of opponents.

\section{Study 2a}

\section{Method and Materials}

Participants. Four-hundred sixty American residents with at least 50 completed HITs and an approval rating above 90\% voluntarily participated in this study on Amazon's Mechanical Turk (AMT) for monetary compensation. Nineteen participants failed at least one of two attention checks described below, so data were analyzed with the remaining 441 individuals $\left(M_{\mathrm{age}}=35\right.$ years, $S D=10$, range age $=[19,74], 188$ females, 251 males $)$. As in previous studies, our primary analyses involve Pearson's correlation, and we aimed to recruit 145 participants per issue (after exclusions) to have $95 \%$ power to detect medium-sized effects $(r=+/-.30)$.

Materials and procedure. The materials and procedure in Study 2a were the same as in Study 1a, with one key difference: instead of answering questions assessing the perceived intellectual capabilities, moral character, and overall impressions of political opponents, we 
asked participants to report their willingness to be friends with political opponents. Specifically, participants indicated the extent to which they agreed or disagreed with the statement, "I could still be friends with someone who chose the position that I did not choose," by responding on a 5-pt scale (1=strongly disagree, 5=strongly agree). The only other difference between Studies 1a and $2 \mathrm{a}$ was that, in Study 2a, only the intellectual humility scale developed by Leary and colleagues (2017) was administered to participants (not the CIHS from Krumrei-Mancuso \& Rouse, 2016). The same attention check item originally embedded in the CIHS in Study 1a was placed in the intellectual humility scale from Leary et al. (2017) in Study 2a.

\section{Results}

For the key variables of interest, Table 9 provides descriptive statistics and reliabilities split by political issue.

Table 9. Means, Standard Deviations, and Reliabilities in Study $2 a$.

\begin{tabular}{lllll}
\hline Issue & Measure & Mean & SD & $\boldsymbol{\alpha}$ \\
\hline Abortion $(n=147)$ & IH (Leary et al.) & 3.92 & .72 & .86 \\
& Friendship with Opponents & 4.01 & 1.17 & \\
Concealed Carry $(n=151)$ & IH (Leary et al.) & 3.97 & .70 & .83 \\
& Friendship with Opponents & 4.37 & .81 & \multirow{2}{*}{ Immigration $(n=143)$} \\
& IH (Leary et al.) & 4.09 & .64 & .83 \\
\hline
\end{tabular}

Note. Total $N=441$

Zero-order correlations. First, bivariate, zero-order correlation analyses were conducted to examine the relations between IH and the friendship measure, split by issue (abortion, concealed carry, immigration). IH was significantly related to participants' willingness to be friends with political opponents for abortion $(r(145)=.23, p=.005)$, concealed carry $(r(149)=$ $.48, p<.001)$, and immigration $(r(141)=.24, p=.004)$. For all three issues, those higher in IH tended to report an increased willingness to befriend political opponents. 
Stepwise regressions. We next computed stepwise hierarchical mixed-effects models to further investigate the effects on IH on participants' willingness to befriend political opponents. In these models, issue (abortion, concealed carry, immigration) was included as a random effect. Then, we computed separate stepwise hierarchical regressions for each issue, separately.

First, only IH was included as a fixed-effects term predicting participants' willingness to be friends with political opponents in Step 1. In all models, issue was included as a random effect. In Step 2, we included age, gender $(0=$ male, $1=$ female $)$, and education as additional fixed effects. Finally, in Step 3, we included the three political variables as fixed effects in the model: political leaning $(1=$ very liberal, 7 = very conservative $)$, party affiliation (Democrat, Republican, Other), and importance of party affiliation to personal identity ( $1=$ not at all important, 7 = very important). At each step, IH continued was strongly, and significantly predictive of participants' willingness to be friends with political opponents (all $p s<.001$ ). See Supplementary Table 11 for full results.

This same process was then repeated, within a multiple regression framework, for all three issues, separately. The results suggest that, for all three issues, and after each step in the stepwise regression, IH was a strong, significant predictor of participants' willingness to be friends with political opponents (see Table 10). 
Table 10. Results from stepwise regression models split by issue in Study $2 a$.

\begin{tabular}{|c|c|c|c|c|c|c|c|}
\hline \multirow[b]{2}{*}{ Issue } & \multirow[b]{2}{*}{ Variables } & \multicolumn{2}{|c|}{ Step 1} & \multicolumn{2}{|c|}{ Step 2} & \multicolumn{2}{|c|}{ Step 3} \\
\hline & & $b(S E)$ & $95 \% \mathrm{CI}$ & $b(S E)$ & $95 \% \mathrm{CI}$ & $b(S E)$ & $95 \% \mathrm{CI}$ \\
\hline \multirow[t]{9}{*}{ Abortion } & $\mathrm{IH}$ & $.37(.13)^{* *}$ & {$[.11, .63]$} & $.41(.13)^{* *}$ & {$[.15, .67]$} & $.37(.14) * *$ & {$[.10, .64]$} \\
\hline & Age & & & $.00(.01)$ & {$[-.02, .02]$} & $.00(.01)$ & {$[-.02, .02]$} \\
\hline & Gender & & & $-.12(.19)$ & {$[-.50, .26]$} & $-.04(.19)$ & {$[-.41, .34]$} \\
\hline & Education & & & $-.14(.09)$ & {$[-.32, .03]$} & $-.13(.09)$ & {$[-.30, .05]$} \\
\hline & Political Leaning & & & & & $.01(.06)$ & {$[-.11, .12]$} \\
\hline & Party Affiliation & & & & & $.44(.26)$ & {$[-.08, .97]$} \\
\hline & [T. Republican] & & & & & & \\
\hline & Party Affiliation & & & & & $.10(.27]$ & {$[-.44, .63]$} \\
\hline & $\begin{array}{l}\text { [T. Other] } \\
\text { Political Identity }\end{array}$ & & & & & $-.10(.05)$ & {$[-.21, .00]$} \\
\hline \multirow{9}{*}{$\begin{array}{l}\text { Concealed } \\
\text { Carry }\end{array}$} & $\mathrm{IH}$ & $.55(.08)^{* * *}$ & {$[.38, .71]$} & $.55(.08)^{* * *}$ & {$[.39, .71]$} & $.56(.08) * * *$ & {$[.39, .72]$} \\
\hline & Age & & & $.01(.01)^{*}$ & {$[.00, .02]$} & $.01(.01)^{*}$ & {$[.00, .02]$} \\
\hline & Gender & & & $-.01(.11)$ & {$[-.24, .22]$} & $.01(.11)$ & {$[-.22, .23]$} \\
\hline & Education & & & $-.11(.06)$ & {$[-.22, .00]$} & $-.09(.06)$ & {$[-.20, .02]$} \\
\hline & Political Leaning & & & & & $.01(.04)$ & {$[-.07, .10]$} \\
\hline & Party Affiliation & & & & & $.24(.18)$ & {$[-.11, .59]$} \\
\hline & [T. Republican] & & & & & & \\
\hline & $\begin{array}{l}\text { Party Affiliation } \\
\text { [T. Other] }\end{array}$ & & & & & $-.01(.15)$ & {$[-.31, .29]$} \\
\hline & Political Identity & & & & & $-.07(.03)^{*}$ & {$[-.14,-.01]$} \\
\hline \multirow{9}{*}{$\begin{array}{l}\text { Immigra- } \\
\text { tion }\end{array}$} & $\mathrm{IH}$ & $.41(.14)^{* *}$ & {$[.13, .68]$} & $.41(.14)^{* *}$ & {$[.13, .68]$} & $.36(.13) * *$ & {$[.10, .62]$} \\
\hline & Age & & & $.00(.01)$ & {$[-.02, .02]$} & $.01(.01)$ & {$[-.01, .02]$} \\
\hline & Gender & & & $-.11(.18)$ & {$[-.47, .25]$} & $.01(.18)$ & {$[-.34, .36]$} \\
\hline & Education & & & $-.04(.08)$ & {$[-.21, .12]$} & $-.05(.08)$ & {$[-.21, .11]$} \\
\hline & Political Leaning & & & & & $.13(.05)^{*}$ & {$[.02, .23]$} \\
\hline & Party Affiliation & & & & & $-.10(.25)$ & {$[-.61, .40]$} \\
\hline & $\begin{array}{l}\text { [1. Kepublican] } \\
\text { Party Affiliation }\end{array}$ & & & & & $-.13(.23)$ & {$[-.59, .33]$} \\
\hline & [T. Other] & & & & & & \\
\hline & Political Identity & & & & & $-.17(.05)^{* * *}$ & {$[-.27,-.08]$} \\
\hline
\end{tabular}

Note. ${ }^{* * *} p<.001, * * p<.01, * p<.05$. The outcome variable in all models is participants' willingness to be friends with political opponents. All 95\% CIs are around beta-estimates.

Collectively, these results corroborate our second hypothesis that, at least for highly contentious, polarized sociopolitical issues, low-IH individuals are less willing than high-IH individuals to befriend those who hold opposing sociopolitical views. Even after statistically controlling for several demographics variables and several variables assessing participants’ political beliefs and orientations, these effects held at a similar magnitude. 


\section{Study 2b}

\section{Method and Materials}

Participants. Six-hundred twenty American residents with at least 50 completed HITs and an approval rating above $90 \%$ voluntarily participated in this study on Amazon's Mechanical Turk (AMT) for monetary compensation. In Study 2b, we increased the sample size because we expected the effects of IH on participants' willingness to be friends with political opponents to be smaller for less-charged/contentious issues than for the polarized, contentious issues. The sample size was determined prior to running the study, as noted in the pre-registration (https://osf.io/yudz7/). Twenty-one participants failed at least one of two attention checks described below, so data were analyzed with the remaining 599 individuals $\left(M_{\text {age }}=38\right.$ years, $S D=13$, range age $=[18,88], 292$ females, 302 males $)$.

Materials and procedure. The materials and procedure in Study $2 \mathrm{~b}$ were the same as in Study 2a, with one key difference: in Study 2b, we used the three less-charged/contentious political issues - drone strikes on military targets overseas, fracking, and standardized testing in schools - that were used in Study 1b, instead of the more-polarized/contentious political issues used in Studies 1a and 2a.

\section{Results}

For the key variables of interest, Table 11 provides descriptive statistics and reliabilities split by political issue.

Table 11. Means, Standard Deviations, and Reliabilities in Study $2 b$.

\begin{tabular}{lllll}
\hline Issue & Measure & Mean & SD & $\boldsymbol{\alpha}$ \\
\hline Drone Strikes $(n=201)$ & IH (Leary et al.) & 3.94 & .71 & .85 \\
& Friendship with Opponents & 4.44 & .89 & \\
Fracking $(n=199)$ & IH (Leary et al.) & 4.02 & .67 & .83 \\
\multirow{2}{*}{ Standardized Testing $(n=199)$} & Friendship with Opponents & 4.46 & .80 & \\
& IH (Leary et al.) & 4.09 & .63 & .83 \\
\hline & Friendship with Opponents & 4.64 & .62 & \\
\hline
\end{tabular}

Note. Total $N=599$ 
Zero-order correlations. First, bivariate, zero-order correlations were computed between IH and the friendship measure, split by issue (drone strikes, fracking, standardized testing). IH was significantly related to the participants' willingness to be friends with political opponents for drone strikes $(r(199)=.35, p<.001)$, fracking $(r(197)=.24, p=.001)$, and standardized testing $(r(197)=.16, p=.024)$. For all three issues, those higher in IH were consistently more willing to befriend political opponents.

Stepwise regressions. We next computed stepwise hierarchical mixed-effects models to further investigate the effects on IH on participants' willingness to be friends with political opponents. In these models, issue (drone strikes, fracking, standardized testing) was included as a random effect. Then, we computed separate stepwise hierarchical regressions for each issue separately.

In Step 1, only IH was included as a fixed-effects term predicting participants' willingness to be friends with political opponents. In all models, issue was included as a random effect. In Step 2, we included age, gender $(0=$ male, $1=$ female $)$, and education as additional fixed effects. Finally, in Step 3, we included the three political variables as fixed effects in the model: political leaning $(1=$ very liberal, $7=$ very conservative $)$, party affiliation (Democrat, Republican, Other), and importance of party affiliation to personal identity ( $1=$ not at all important, $7=$ very important $)$. At each step, $\mathrm{IH}$ was a robust, significant predictor of participants' willingness to be friends with political opponents (all $p$ s $<.001$ ). See Supplementary Table 12 for full results.

This same process was then repeated, within a multiple regression framework, for all three issues, separately. For all three issues, and after each step in the regression, IH continued to significantly predict participants' willingness to befriend political opponents (see Table 12). 
Table 12. Results from stepwise regression models split by issue in Study $2 b$.

\begin{tabular}{|c|c|c|c|c|c|c|c|}
\hline \multirow[b]{2}{*}{ Issue } & \multirow[b]{2}{*}{ Variables } & \multicolumn{2}{|c|}{ Step 1} & \multicolumn{2}{|c|}{ Step 2} & \multicolumn{2}{|c|}{ Step 3} \\
\hline & & $b(S E)$ & $95 \% \mathrm{CI}$ & $b(S E)$ & $95 \% \mathrm{CI}$ & $b(S E)$ & $95 \% \mathrm{CI}$ \\
\hline \multirow{10}{*}{$\begin{array}{l}\text { Drone } \\
\text { Strikes }\end{array}$} & $\mathrm{IH}$ & $.44(.08)^{* * *}$ & {$[.28, .60]$} & $.47(.08)^{* * *}$ & {$[.31, .62]$} & $.46(.08)^{* * * *}$ & {$[.30, .63]$} \\
\hline & Age & & & $.01(.00)$ & {$[.00, .02]$} & $.01(.00)$ & {$[.00, .02]$} \\
\hline & Gender & & & $.11(.11)$ & {$[-.12, .33]$} & $.13(.12)$ & {$[-.10, .36]$} \\
\hline & Education & & & $.07(.05)$ & {$[-.04, .17]$} & $.08(.05)$ & {$[-.03, .19]$} \\
\hline & Political & & & & & $-.02(.05)$ & {$[-.11, .08]$} \\
\hline & Leaning & & & & & & \\
\hline & Party Affiliation & & & & & $.31(.21)$ & {$[-.09, .72]$} \\
\hline & [T. Republican] & & & & & & \\
\hline & $\begin{array}{l}\text { Party Affiliation } \\
\text { [T. Other] }\end{array}$ & & & & & $.21(.15)$ & {$[-.09, .50]$} \\
\hline & Political Identity & & & & & $-.01(.03)$ & {$[-.08, .05]$} \\
\hline \multirow[t]{10}{*}{ Fracking } & $\mathrm{IH}$ & $.28(.08)^{* * *}$ & {$[.12, .45]$} & $.27(.08)^{* *}$ & {$[.11, .43]$} & $.26(.08)^{* *}$ & {$[.10, .43]$} \\
\hline & Age & & & $.01(.01)$ & {$[.00, .02]$} & $.01(.00)$ & {$[.00, .02]$} \\
\hline & Gender & & & $-.29(.11)^{* *}$ & {$[-.51,-.07]$} & $-.27(.11)^{*}$ & {$[-.48,-.05]$} \\
\hline & Education & & & $-.07(.05)$ & {$[-.17, .04]$} & $-.03(.05)$ & {$[-.14, .08]$} \\
\hline & Political & & & & & $.07(.05)$ & {$[-.02, .16]$} \\
\hline & Leaning & & & & & & \\
\hline & $\begin{array}{l}\text { Party Affiliation } \\
\text { [T. Republican] }\end{array}$ & & & & & $.11(.21)$ & {$[-.31, .52]$} \\
\hline & Party Affiliation & & & & & $-.07(.15)$ & {$[-.36, .22]$} \\
\hline & [T. Other] & & & & & & \\
\hline & Political Identity & & & & & $-.08(.03) *$ & {$[-.14,-.02]$} \\
\hline \multirow{10}{*}{$\begin{array}{l}\text { Standardized } \\
\text { Testing }\end{array}$} & $\mathrm{IH}$ & $.16(.07)^{*}$ & {$[.02, .29]$} & $.14(.07)^{*}$ & {$[.01, .28]$} & $.14(.07)^{*}$ & {$[.00, .29]$} \\
\hline & Age & & & $.00(.00)$ & {$[-.01, .00]$} & $.00(.00)$ & {$[-.01, .00]$} \\
\hline & Gender & & & $.09(.09)$ & {$[-.08, .27]$} & $.08(.09)$ & {$[-.09, .26]$} \\
\hline & Education & & & $-.01(.04)$ & {$[-.09, .07]$} & $.00(.04)$ & {$[-.08, .08]$} \\
\hline & Political & & & & & $-.11(.04)^{*}$ & {$[-.19,-.02]$} \\
\hline & Leaning & & & & & & \\
\hline & $\begin{array}{l}\text { Party Affiliation } \\
\text { [T. Republican] }\end{array}$ & & & & & $.36(.19)$ & {$[-.01, .72]$} \\
\hline & Party Affiliation & & & & & $.25(.13)$ & {$[-.01, .50]$} \\
\hline & [T. Other] & & & & & & \\
\hline & Political Identity & & & & & $.01(.03)$ & {$[-.04, .06]$} \\
\hline
\end{tabular}

Note. ${ }^{* * *} p<.001, * * p<.01, * p<.05$. The outcome variable in all models is participants' willingness to be friends with political opponents. All $95 \%$ CIs are around beta-estimates.

These results extend our findings from Study 2 a using a set of less-contentious, lesspolarized sociopolitical issues. For all three issues, low-IH participants were less willing than high-IH participants to befriend those who hold opposing views. These effects held at a similar magnitude even after statistically controlling for several different demographics variables and several variables assessing participants' political beliefs and orientations. Moreover, the effects of IH on willingness to befriend those with opposing views were qualitatively smaller, on 
average, for the non-polarized issues used in Study $2 b$ than for the more-charged, more-polarized issues used in Study 2a. Nevertheless, we found significant effect of IH on willingness to befriend opponents for all six issues examined.

\section{Study 3a}

\section{Method and Materials}

Participants. Four-hundred twenty American residents with at least 50 completed HITs and an approval rating above 90\% voluntarily participated in this study on Amazon's Mechanical Turk (AMT) for monetary compensation. Fourteen participants failed the attention check at the end, and 35 participants failed at least one of two true/false attention check questions (see below for details); so, data were analyzed with the remaining 371 individuals ( $M_{\mathrm{age}}=37.27$ years, $S D=11.18$, range $_{\text {age }}=[18,76], 160$ females, 206 males $)$.

Materials and procedure. The concealed carry of firearms issue used in Studies 1a and 2a was also used in Study 3a. As before, participants read neutral background information about the issue, after which they were instructed to take an initial position by making a binary choice. Then, participants were randomly assigned to the experimental or control condition. In the experimental condition, participants were provided with a definition of intellectual humility, and were then told that our research team at Duke University had conducted several studies to investigate possible differences in intellectual humility between people who select the two possible positions on the concealed carry of firearms issue. Participants were told that we found no differences in intellectual humility between those who select the two respective positions on the concealed carry of firearms issue (indeed, there were no differences on IH between those who selected the two respective positions, $p s>.10$ ). This entails that those who select either position on the concealed carry of firearms are similarly like to recognize that their positions 
might be wrong (see pre-registration for exact wording). Note that participants received no information about whether liberals or conservatives (or Democrats or Republicans) tend to favor one position or the other. To ensure that they comprehended this information, participants then completed two true/false questions with feedback about the material they were instructed to read. Those who incorrectly responded to at least one of these true/false questions were excluded from our analyses. In the control condition, participants were not provided with any information about our previous studies.

All participants rated the extent to which they agree or disagree that the person who holds the other possible position on the concealed carry of firearms issue is (1) unintelligent, (2) irrational, and (3) ignorant on 5-pt scales $(1=$ strongly disagree, $5=$ strongly agree $)$. As in Studies $1 \mathrm{a}$ and $1 \mathrm{~b}$, responses to these three questions were averaged to form a composite measure indexing perceived intellectual capabilities (see Table $\mathbf{1 3}$ for descriptive statistics and reliabilities). Participants were also asked the degree to which they agree or disagree that the person who holds the other possible position on the concealed carry of firearms issue is (1) unethical, (2) immoral, and (3) of bad moral character on 5-pt scales $(1=$ strongly disagree, $5=$ strongly agree). As in Studies 1a and 1b, responses to these three questions were averaged to form a composite measure indexing perceived moral character (see Table 13 for descriptive statistics and reliabilities). Finally, participants were asked to indicate the extent to which they agree or disagree with two friendship questions ( 1 = strongly disagree, $5=$ strongly agree $)$ : (1) I could still be friends with someone who chose the option that I did not choose; and (2) I am willing to befriend those who chose the option that I did not choose. These two questions were averaged to form a friendship with opponents composite (see Table $\mathbf{1 3}$ for descriptive statistics and reliabilities). Note that we used two items to measure friendship with opponents (as opposed 
to the single item used in previous studies); this was done to reduce the likelihood of potential problems with a single item. Across participants, we randomized the order in which these eight questions were presented.

Participants then responded to demographics questions. As in the previous studies, participants were asked the same attention-check question at the end, and we excluded participants who reported being distracted, having trouble paying attention, failing to avoid distractions, and not taking the survey seriously. Upon completion, participants were monetarily compensated for their time.

\section{Results}

Table 13 provides descriptive statistics and reliabilities split by condition (experimental versus control).

Table 13. Means, Standard Deviations, and Reliabilities in Study $3 a$.

\begin{tabular}{lllll}
\hline Issue & Measure & Mean & SD & $\boldsymbol{\alpha}$ \\
\hline Experimental Condition $(n=164)$ & Intellectual Capabilities of Opponents & 2.29 & 1.14 & .91 \\
& Moral Character of Opponents & 2.16 & 1.12 & .95 \\
& Friendship with Opponents & 4.07 & .93 & .74 \\
Control Condition $(n=207)$ & Intellectual Capabilities of Opponents & 2.69 & 1.26 & .90 \\
& Moral Character of Opponents & 2.42 & 1.15 & .93 \\
& Friendship with Opponents & 3.89 & 1.06 & .81 \\
\hline
\end{tabular}

Note. Total $N=371$

We hypothesized that informing participants that people who hold different positions on an issue do not actually differ on IH will render them less likely to derogate their opponents and more willing to befriend their opponents. An initial $t$-test revealed that those assigned to the experimental condition, relative to the control condition, were less likely to derogate the intellectual capabilities of opponents $(t(369)=3.17, p=.002,95 \%$ CI $[.15, .65])$. Similarly, another $t$-test revealed that those assigned to the experimental condition, relative to the control condition, were less likely to derogate the moral character of opponents $(t(369)=2.12, p=.034$, 95\% CI $[.02, .49])$. However, a final $t$-test revealed that the effect of condition on the friendship 
with opponents composite was not significant $(t(369)=1.70, p=.090,95 \%$ CI [-.03, .39]), but there was a trend in the expected direction note that this effect was significant with a one-tailed $t$ test in the direction we hypothesized). Figure 1 graphically depicts these results.

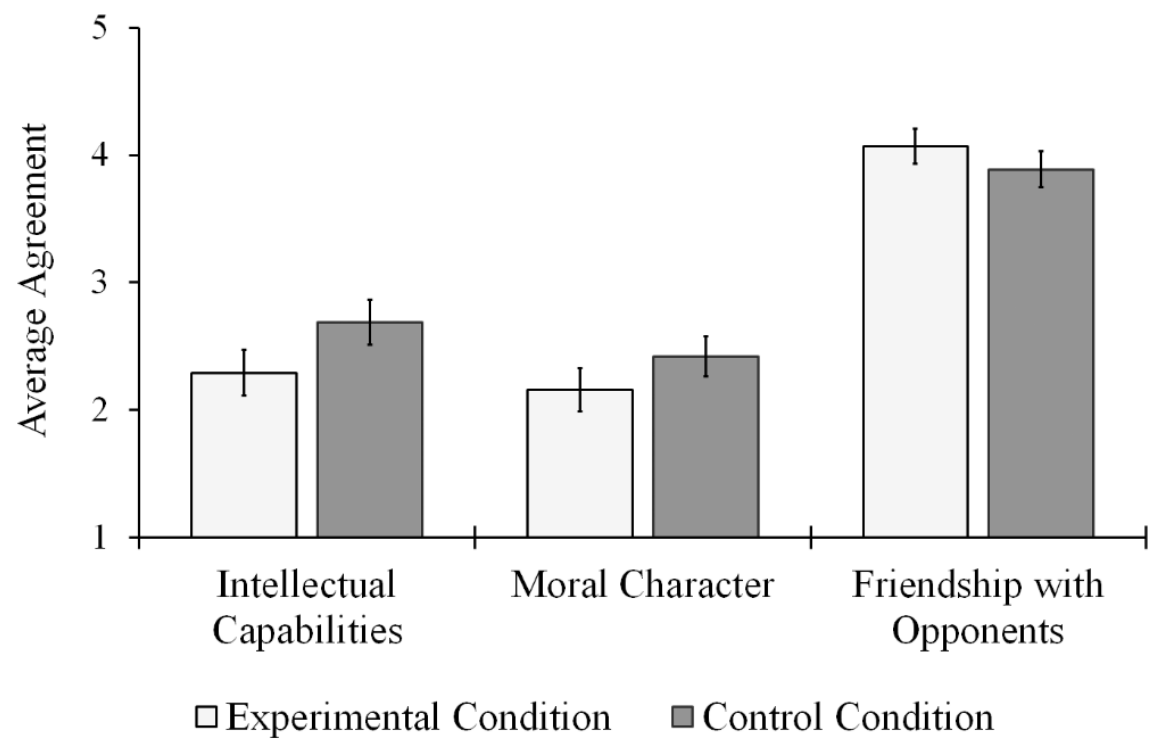

Figure 1. In Study 3a, average agreement ratings for composites indexing intellectual capabilities of opponents, moral character of opponents, and friendship with opponents as a function of condition (experimental versus control). Informing participants that opponents on the concealed carry issue do not actually differ on IH rendered them less likely to derogate their opponents and somewhat more willing to befriend their opponents. Error bars represent $95 \%$ CIs around means.

\section{Study 3b}

\section{Method and Materials}

Participants. Four-hundred twenty American residents with at least 50 completed HITs and an approval rating above 90\% voluntarily participated in this study on Amazon's Mechanical 
Turk (AMT) for monetary compensation. Eleven participants failed the attention check at the end, 3 participants submitted the HIT without answering any of the DVs, and 34 participants failed at least one of two true/false attention check questions (see below for details); so, data were analyzed with the remaining 376 individuals $\left(M_{\mathrm{age}}=36.92\right.$ years, $S D=10.91$, range $_{\text {age }}=[20,76], 186$ females, 188 males $)$.

Materials and procedure. The standardized testing issue used in Studies $1 b$ and $2 b$ was also used in Study 3b. Note that there were no differences on IH between those who selected the two respective positions on the standardized testing issue in our previous studies $(p s>.10)$.

Aside from the difference in the issue used, the procedure and experimental design in Study $3 b$ were the same as in Study $3 a$.

\section{Results}

Table 14 provides descriptive statistics and reliabilities split by condition (experimental versus control).

Table 14. Means, Standard Deviations, and Reliabilities in Study $3 b$.

\begin{tabular}{lllll}
\hline Issue & Measure & Mean & SD & $\boldsymbol{\alpha}$ \\
\hline Experimental Condition $(n=164)$ & Intellectual Capabilities of Opponents & 1.82 & 1.01 & .92 \\
& Moral Character of Opponents & 1.65 & 1.00 & .96 \\
& Friendship with Opponents & 4.49 & .76 & .67 \\
Control Condition $(n=212)$ & Intellectual Capabilities of Opponents & 2.16 & 1.08 & .92 \\
& Moral Character of Opponents & 1.83 & .99 & .92 \\
& Friendship with Opponents & 4.30 & .93 & .81 \\
\hline
\end{tabular}

Note. Total $N=376$

As in Study 3a, we implemented an experimental manipulation by informing participants that those who hold different positions on an issue do not actually differ on IH. We investigated whether this manipulation renders participants less likely to derogate their opponents, and more willing to befriend their opponents. An initial $t$-test revealed that those assigned to the experimental condition, relative to the control condition, were less likely to derogate the intellectual capabilities of opponents $(t(374)=3.07, p=.002,95 \%$ CI $[.12, .55])$. However, 
another $t$-test revealed that the experimental manipulation did not render participants significantly less likely to derogate the moral character of opponents $(t(374)=1.76, p=.079$, $95 \%$ CI $[-.02, .39])$, but there was a trend in the expected direction (note that this effect was significant with a one-tailed $t$-test in the direction we hypothesized). A final $t$-test revealed that those assigned to the experimental condition, relative to the control condition, were significantly more willing to befriend opponents $(t(374)=2.17, p=.031,95 \%$ CI $[.02, .37])$. Figure 2 graphically depicts these results.

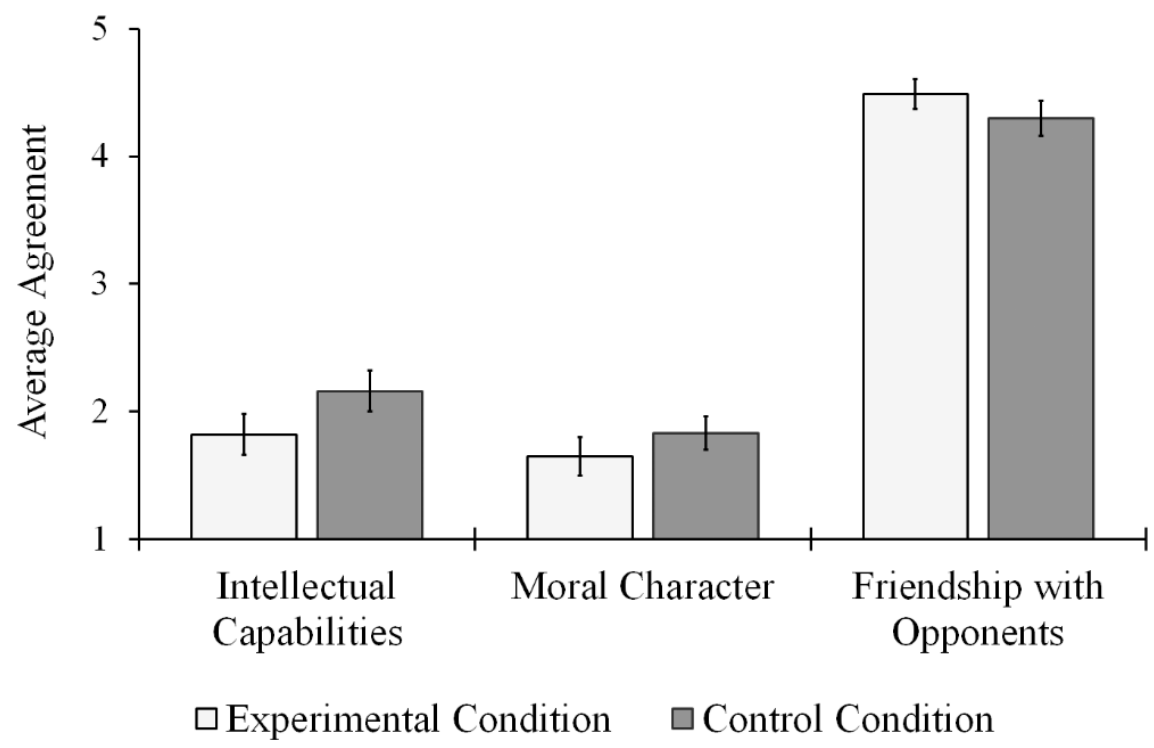

Figure 2. In Study 3b, average agreement ratings for composites indexing intellectual capabilities of opponents, moral character of opponents, and friendship with opponents as a function of condition (experimental versus control). Informing participants that opponents on the standardized testing issue do not actually differ on IH rendered them less likely to derogate their opponents and more willing to befriend their opponents. Error bars represent $95 \%$ CIs around means. 


\section{General Discussion}

In Studies 1a and 1b, we investigated a possible way in which people who are low in IH might be overconfident in their beliefs and particularly unwilling to seriously engage with opponents' views. For five of the six sociopolitical issues examined, we found that participants lower in IH tended to derogate the intellectual capabilities and moral character of sociopolitical opponents more than participants higher in IH. By believing that opponents are unintelligent and unethical, it may become easier to dismiss others' views and to believe in the superiority of one's own views. Studies $2 \mathrm{a}$ and $2 \mathrm{~b}$ examined whether participants lower in $\mathrm{IH}$ are less willing to befriend people with opposing views. For both highly-contentious, polarized issues, and lesscontentious, polarized issues, those lower in $\mathrm{IH}$ were indeed less willing than those higher in $\mathrm{IH}$ to befriend people who hold opposing positions.

Then, in Studies 3a and 3b, we introduced an experimental manipulation to explore a possible way to render participants less likely to derogate opponents and more willing to befriend opponents. We informed participants that there are actually no differences in IH between people who hold opposing positions on the issues, and we tested whether this information influenced their perceptions of their opponents. For both issues examined, informing participants that opponents do not actually differ on IH made participants derogate opponents less. Moreover, for the standardized testing issue, but not for the concealed carry issue, informing participants that those who hold opposing positions do not differ on IH made them more willing to befriend those with opposing views. The results from these two final studies provide experimental evidence for a simple and effective means of reducing the tendency for people to derogate others who hold different sociopolitical views. 
There has been a recent surge of research on $\mathrm{IH}$, much of which has been devoted to $\mathrm{IH}$ scale development and validation (e.g., Haggard et al., 2018; Krumrei-Mancuso \& Rouse, 2016; Leary et al., 2017). By most psychological accounts, IH is fundamentally a cognitive intrapersonal construct reflecting people's private assessments of their beliefs and attitudes (Leary et al., 2017). There are, however, important interpersonal consequences of differences in IH. Other research has found that those higher in IH tend to be more forgiving (Lavelock et al., 2014), generous (Exline \& Hill, 2012), and empathic (Krumrei-Mancuso \& Rouse, 2016). Our research expands upon these findings by identifying an interpersonal consequence of differences in $\mathrm{IH}$, namely that those low in IH tend to both derogate sociopolitical opponents and express an unwillingness to befriend people with opposing sociopolitical views.

Our finding that $\mathrm{IH}$ predicts the degree to which people derogate sociopolitical opponents and express an unwillingness to befriend them may have significant implications for social extremism and political polarization. Derogating opponents and being unwilling to befriend them might create cliques of people, with the same views, who collectively seek out and share information that reinforces their shared views (i.e., "echo chambers"). With contemporary social media, there is no shortage of opportunities for people to create and find their desired echo chambers. In fact, echo chambers comprised of people discussing sociopolitical issues and events have been identified on Twitter (Barberá, et al., 2015; Williams, McMurray, Kurz, \& Lambert, 2015), Facebook (Del Vicario, et al., 2016), and various blogs (Suhay, Blackwell, Roche, \& Bruggeman, 2015). Critically, the results of our final two studies suggest that informing people about actual psychological research on IH has the potential to make them less likely to derogate opponents and more willing to befriend them. This kind of simple intervention might help to minimize social extremism and political polarization - especially for low-IH individuals. 
Disagreements over sociopolitical issues can be useful and fruitful. Such disagreements offer the potential for understanding the perspectives of others, generating creative solutions to significant problems, and growing intellectually. However, the extent to which disagreements are useful depends on the willingness of opposing sides to try to understand opposing positions (de Wied, Branje, \& Meeus, 2007; Stone, Patton, \& Heen, 2010). Promoting IH as an epistemic virtue worth cultivating and informing the public about research on IH has the potential to reduce social extremism, polarization, and the frequency of unresolvable disagreements over time.

\section{Declaration of Conflicting Interests}

The authors declared that they had no conflicts of interest with respect to their authorship or the publication of this article.

\section{Author Contributions}

All authors contributed to study design. Data collection and analyses were performed by M. L. Stanley. All authors were involved in interpretation. M. L. Stanley drafted the manuscript, and A. H. Sinclair and P. Seli provided critical revisions. All authors approved the final version of the manuscript for submission.

\section{Acknowledgments}

We thank Dr. Mark Leary for helpful feedback and comments. 


\section{References}

Barberá, P., Jost, J. T., Nagler, J., Tucker, J. A., \& Bonneau, R. (2015). Tweeting from left to right: Is online political communication more than an echo chamber?. Psychological Science, 26(10), 1531-1542.

Bates, D., Maechler, M., Bolker, B., \& Walkers, S. (2014). lme4: Linear mixed-effects models using Eigen and S4. Retrieved from https://cran.r-project.org/ packagelme4

de Wied, M., Branje, S. J., \& Meeus, W. H. (2007). Empathy and conflict resolution in friendship relations among adolescents. Aggressive Behavior, 33(1), 48-55.

Del Vicario, M., Vivaldo, G., Bessi, A., Zollo, F., Scala, A., Caldarelli, G., \& Quattrociocchi, W. (2016). Echo chambers: Emotional contagion and group polarization on facebook. Scientific Reports, 6, 37825.

Deffler, S. A., Leary, M. R., \& Hoyle, R. H. (2016). Knowing what you know: Intellectual humility and judgments of recognition memory. Personality and Individual Differences, 96, 255-259.

Exline, J. J., \& Hill, P. C. (2012). Humility: A consistent and robust predictor of generosity. The Journal of Positive Psychology, 7(3), 208-218.

Haggard, M., Rowatt, W. C., Leman, J. C., Meagher, B., Moore, C., Fergus, T., ... \& HowardSnyder, D. (2018). Finding middle ground between intellectual arrogance and intellectual servility: Development and assessment of the limitations-owning intellectual humility scale. Personality and Individual Differences, 124, 184-193.

Iyengar, S., \& Hahn, K. S. (2009). Red media, blue media: Evidence of ideological selectivity in media use. Journal of Communication, 59(1), 19-39. 
Krumrei-Mancuso, E. J. (2017). Intellectual humility and prosocial values: Direct and mediated effects. The Journal of Positive Psychology, 12(1), 13-28.

Krumrei-Mancuso, E. J., \& Rouse, S. V. (2016). The development and validation of the comprehensive intellectual humility scale. Journal of Personality Assessment, 98(2), 209221.

Kunda, Z. (1990). The case for motivated reasoning. Psychological Bulletin, 108, 480-498.

Lavelock, C. R., Worthington Jr, E. L., Davis, D. E., Griffin, B. J., Reid, C. A., Hook, J. N., \& Van Tongeren, D. R. (2014). The quiet virtue speaks: An intervention to promote humility. Journal of Psychology and Theology, 42(1), 99-110.

Leary, M. R., Diebels, K. J., Davisson, E. K., Jongman-Sereno, K. P., Isherwood, J. C., Raimi, K. T., ... \& Hoyle, R. H. (2017). Cognitive and interpersonal features of intellectual humility. Personality and Social Psychology Bulletin, 43(6), 793-813.

Lodge, M., \& Taber, C. S. (2013). The rationalizing voter. Cambridge University Press.

Meagher, B. R., Leman, J. C., Bias, J. P., Latendresse, S. J., \& Rowatt, W. C. (2015). Contrasting self-report and consensus ratings of intellectual humility and arrogance. Journal of Research in Personality, 58, 35-45.

Porter, T., \& Schumann, K. (2018). Intellectual humility and openness to the opposing view. Self and Identity, 17(2), 139-162.

Stanley, M. L., Henne, P., Yang, B. W., \& De Brigard, F. (in press). Resistance to position change, motivated reasoning, and polarization. Political Behavior.

Stone, D., Heen, S., \& Patton, B. (2010). Difficult conversations: How to discuss what matters most. Penguin. 
Suhay, E., Blackwell, A., Roche, C., \& Bruggeman, L. (2015). Forging bonds and burning bridges: Polarization and incivility in blog discussions about Occupy Wall Street. American Politics Research, 43(4), 643-679.

Taber, C. S., \& Lodge, M. (2006). Motivated skepticism in the evaluation of political beliefs. American Journal of Political Science, 50(3), 755-769.

Williams, H. T., McMurray, J. R., Kurz, T., \& Lambert, F. H. (2015). Network analysis reveals open forums and echo chambers in social media discussions of climate change. Global Environmental Change, 32, 126-138. 